\title{
Adaptive Morphology of the Mystacial Vibrissae in the African Giant Pouched Rat (Cricetomys gambi- anus, Waterhouse-1840)
}

\author{
${ }^{1 *}$ Chikera S. Ibe, ${ }^{1}$ Barth I. Onyeanusi, ${ }^{1}$ Suleiman O. Salami and \\ ${ }^{2}$ Itopa E. Ajayi \\ ${ }^{1}$ Department of Veterinary Anatomy, Ahmadu Bello University Zaria, Nigeria \\ ${ }^{2}$ Department of Veterinary Anatomy, University of Abuja, Abuja, Nigeria
}

Received August, accepted for publication October 2010

\section{Abstract}

Anatomy of the mystacial vibrissae in the African giant pouched rat was investigated to establish the role played by these structures in the adaptation of the rodent to its subterranean environment. Gross morphology was based on direct observation of the mystacial vibrissae with the naked eyes, while histology was based on light microscopic examination of the same structure stained with haematoxylin and eosin $(\mathrm{H} / \mathrm{E})$, Masson's trichrome (MT) and Masson-Fontana reducing method for melanin. The mystacial vibrissae were aligned in 5-6 rows on each side of the face. The length increased rostrocaudally in each row. The mean number of vibrissae was 55.29 ( \pm 3.42$)$. The vibrissal folliclesinus complex extended into the reticular layer of the dermis. In the proximal part of the sinus, trabeculae of connective tissues connected the internal and external dermal sheaths. The most distal part of the sinus contained blood vessels. The external dermal sheaths were thick and held in position by muscle fibres. Mean thickness of the cortex and medulla in the complex were $1.626 \mu \mathrm{m}( \pm$ $0.110)$ and $0.775 \mu \mathrm{m}( \pm 0.057)$, respectively. The thick external dermal sheaths were laden with mechanoreceptors. The thick cortex provided the needed elasticity necessary for touch and sensation. In conclusion, the well developed mystacial vibrissa in the African giant pouched rat is an important compensation for poor vision, necessary for an effective adaptation.

\section{Key words:}

Gross morphology, histology, mystacial vibrissae, African giant pouched rat. 


\section{Introduction}

Subterranean mammals are morphologically adapted for a permanent underground life (Nevo and Reig, 1990). Their environment is deprived of a number of stimuli, most especially, light. Consequently, specific sensory modifications to cope with living in such an ecotope are expected. Mystacial vibrissae play a vital role in tactile orientation. They are extremely sensitive tactile organs used as both high resolution tactile discriminators (Brecht et al., 1997) and distance detectors (Krupa et al., 2001). Nocturnal animals highly depend on mystacial vibrissae to perceive their close surroundings (Halata, 1993). During exploration, the vibrissae are bilaterally swept against objects and obstacles to gather accurate information about the animal's close surroundings (Krupa et al., 2004). Other suggested functions include depth perception (Schiffman et al., 1970), social dominance (Strozik and Festing, 1981), predatory behaviour (Kemble and Lewis, 1982) and swimming (Ahl, 1982). They are usually thicker and stiffer than other hair types. They are composed of an array of extrinsic and intrinsic muscles (Dörfl, 1982) and sensory nerve endings (Woolsey et al., 1981; Hyvärinen, 1989) that aid in their tactile function. Generally, they commonly grow around the nasal orifice, above the lips, and on other parts of the face of most mammals. They have been reported on the in- ner surfaces of the forelimbs, and on the ventral body in squirrels (Sciurus vulgaris) (Hyvärinen et al., 1976), ulnacarpal joint of the newly named Sulawesian rat (Sommeromys macrorhi-nos) (Musser and Durden, 2002), finger of the Asian elephant (Elephas maximus) (Rasmussen and Munger, 1996) and the rump of Dabbene's mastiff Bat ( $E u$ mops dabbenei) (McWilliams et al., 2002). However, in Murid rodents, they are found only on the head and lower forelimbs (Aplin et al., 2003). Some other mammals may lack external vibrissae as adults but develop them pre-natally only to lose them before birth (Cave, 1969).

Acuity of the visual sense in the African giant pouched rat is poor (Morris, 1963; Ajayi, 1975; Smithers, 1985; Ibe et al., 2010). Thus, it is expected that some other senses will be developed as compensatory mechanisms. Since the mystacial vibrissae is considered an important sensory structure, mediating between the animal and its close surrounding, and since touch is of paramount importance in the dark subterranean, we embarked on this study in the African giant pouched rat to determine the organization of the mystacial vibrissae and the adaptation to burrows. In other rodents, there are similar gross and histo-morphological studies (Hyvärinen, 1972; Young and Oliver, 1976; Dörfl, 1982; Ahl, 1987; Klauer et al., 1997), but to our knowledge, there is no such study for the African giant 
pouched rat. The specific objectives were three fold: 1) to examine the gross features of the vibrissal field in the African giant pouched rat, 2) to describe the light microscopic features of the structure, and 3) to establish a structure-functional paradigm and relate our findings with that of other rodents in the literature.

\section{Materials and Methods}

Intact heads of 7 adult, clinically healthy, African giant pouched rats were utilized for this study. The animals were captured live from the wild in Kaduna state Nigeria, using locally made traps. The traps were made of galvanised metal of $1.3 \mathrm{~m}$ by $0.3 \mathrm{~m}$ by $0.1 \mathrm{~m}$ in dimension. The rats were transported by road in standard laboratory cages to the animal pen in the Department of Veterinary Anatomy, Ahmadu Bello University, Zaria. They were given access to fresh elephant grass (Penicetum puperum), groundnut cake, potatoes and drinking water ad libitum. Characteristics of the mystacial vibrissae, rhinarium and buccal ridge were observed and photographs were taken with a digital camera (14650, Eastman Ko$\operatorname{dak}^{\circledR}$, Rochester, New York, U. S. A.). The number of mystacial vibrissae on each side of the face was counted in each of the animals. The absolute length of the longest vibrissa was measured with a centimetre ruler. Relative vibrissal length was obtained using the method de- scribed by Ahl (1987). The relative vibrissal length was preferred for specie comparison because it adjusts for differences in body size (Ahl, 1987).

In each of the 7 African giant pouched rats, skin grafts of $5 \mathrm{~mm}^{2}$ from shaved portions of the mystacial pad were measured with a Vernier calliper (sensitivity: 0.01mm, MG6001DC, General Tools and Instruments Company, New York, U.S.A.) and cut out. The skin grafts were cut such that the epidermis, dermis, subcutis, deep facia and underlying muscle were intact. The tissues were washed with physiological saline solution and fixed in $10 \%$ phosphatebuffered formalin for 1 week. Thereafter, they were washed in water and kept therein for 24 hours. The tissues were then dehydrated in ascending grades of alcohol, clear-ed in xylene, infiltrated with molten paraffin wax (BDH Chemicals Ltd. Poole, U.K.) at $60{ }^{\circ} \mathrm{C}$, blocked in paraffin according to standard procedures (Kiernan, 1990) and labelled.

The skin grafts were sectioned transversely at $5 \mu \mathrm{m}$ using a Jung rotary microtome (Model 42339, Berlin, Germany). The first few sections to show a good presentation of tissue were mounted on glass slides, dried, deparaffinized, stained, dehydrated, and cover-slipped using DPX mountant. Specifically, alternate sections were stained with 
$H / E$ and MT stains. MT was indicated to demonstrate collagen fibres which stained blue against a black (cell nuclei) and red (cytoplasm, muscles or erythrocytes) background. A paraffin section of each of the skin grafts was treated with the Masson-Fontana reducing method to demonstrate melanin, using the method of Bancroft and Stevens (1990).

The mean thickness of the cortex and medulla of the vibrissal folliclesinus complex were obtained using a calibrated ocular micrometer (Leitz Wetzlar, Germany) following appropriate calibration of a light microscope (OLYMPUS ${ }^{\circledR}$ EUROPA $\mathrm{GmbH}$, XSZ107BN, Hamburg, Germany) with a stage micrometer (Graticules Ltd., London, U.K.). For each animal, cortical and medullary thickness in 3 complexes was obtained and the mean value represented the thickness of the cortex and medulla of the vibrissal folliclesinus complex of the particular animal. This was repeated for the 7 animals. The mean thickness of the cortex and medulla from the 7 animals were compared using student's t-test. Values of $p<0.05$ were considered significant.

Images of these histological sections were photographed with a digital eyepiece (Scopetek ${ }^{\circledR}$ DCM500, Resolution: $5 \mathrm{M}$ pixels) attached to the light microscope. Similar images of other animals found in the literature (Klauer et al., 1997; Yildiz et al.,
2004) were used as references for histological land-marks. Nomina Anatomica Veterinaria (2005) was used for nomenclature.

\section{Results}

\section{Gross morphology}

The mystacial vibrissae were aligned in rows and columns on the mystacial pad and perpendicular to the rostrocaudal extent of the animal (Fig. 1). These were aligned in 5 - 6 rows with 5 - 9 vibrissal hairs per row, on each side of the face. They were of varying length but generally, the length increased rostrocaudally in each row. The longest vibrissa extended beyond the tip of the external ear when directed towards the ear. The mean total number of vibrissae was 55.29 ( \pm 3.42 ), while the absolute and relative lengths of the longest vibrissae

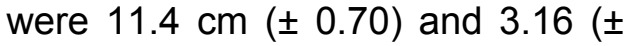
0.18 ), respectively (Table 1 ). Also, there was an average of $27( \pm 1.80)$ and 28.29 ( \pm 2.01 ) vibrissae on the right and left faces, respectively.

\section{Histology}

The vibrissal follicle-sinus complex was well delineated in histologic sections (Fig. 3). Some of the complexes extended into the reticular layer of the dermis, while others extended into the hypo-dermis. The hair follicle, situated inside the sinus, consisted of an outer thick cortex (Fig. 3: C) and an inner thin me- 
dulla (Fig. 3: D). The mean thickness of the cortex and medulla in the complex were $1.626 \mu \mathrm{m}( \pm$ $0.110)$ and $0.775 \mu \mathrm{m}( \pm 0.057)$, respectively, and the difference was very highly significant $(p<0.001)$ (Fig. 2). The cortex was covered by a thin internal dermal sheet (Fig. 3: $G)$ which separated the follicle from the outer sinus (Fig. 3: E). A thick external dermal sheath (Fig. 3: H) enveloped the sinus. Thus, the sinus was located between the internal and the external dermal sheath. Numerous trabeculae of connective tissue (Fig. 3: F; Fig. 4: D) were aligned on the outer surface of the internal dermal sheath, projecting into the sinus. In the proximal part of the sinus, the trabeculae connected the internal and external dermal sheath. Blood vessels were resident within the sinus. The external dermal sheath was made of dense connective tissue, mainly of collagen origin (Fig. 4: G) and held in position by muscle fibres. Merkel cells were observed in higher magnification of the external dermal sheath (Fig. 4: E), and melanocytes were observed in stratum basale of the epidermis and between the collagen fibres. Sweat glands were evident in the hypodermis (Fig. 3).

\section{Discussion}

The mode of action of the vibrissae in tactile function has been elucidated (Dörfl, 1985; Rice et al., 1986;
Marshall et al., 2006). In summary, following stimulation of the free end of the mystacial vibrissae by an object, mechanoreceptors such as Merkel cells in free nerve endings within the internal and external dermal sheaths and in the trabeculae, are activated so that sensory impulses are relayed to the barrel cortex of the brain, through the maxillary branch of the trigeminal nerve and the thalamus. Halata (1993) explained that the mechanoreceptors are most numerous in the external dermal sheaths, surroundding the sinus. The follicle-sinus complex observed in the present study depicts well developed vibrissae. The blood filled sinus of the complex has been reported by Halata (1993) as what differentiates developed vibrissae from other hair types that lack tactile functions. The external dermal sheaths were observed to be very thick and contained Merkel cells. Also, the combination of the dermal sheaths and trabeculae is responsible for the tensile strength of the complex, necessary for the bilateral sweeping of the vibrissae against objects to gather accurate information about the animal's close surroundings. This specific role of the mystacial vibrissae is important to the African giant pouched rat in tactile detection of objects, to compensate for the poor vision of the rodent. The specific organization of the follicle-sinus complex may also provide a level of frictional resistance as the animal moves to and fro in the burrow. The 
follicle-sinus complex observed in the present study also comprised of a better developed cortex than medulla, based on their relative thickness. According to Yanli et al. (1998), the cortex of vibrissa is expected to be very well developed, because its elasticity and tenacity work well in touching and sensing, while the medulla of vibrissa is not usually well developed because vibrissa has been evaluated to fall in warm-keeping function.

The length and thickness of vibrissae constitute the gross specialization necessary for their tactile sense (Yildiz et al., 2004). Ahl (1987) recorded a mean relative vibrissal length of $1.009( \pm 0.055)$ for ground squirrels. Similarly, O'Shea (1991) stated that the relative vibrissal length of Xerus rutilus (the unstiped ground squirrel) is typical of the range reported for ground squirrels by Ahl (1987). The present study recorded a mean relative vibrissal length of 3.16 . This value is by far higher than the value recorded by Ahl (1987) and O'Shea (1991). Ground squirrels are burrowing rodents (Ahl, 1987; O'Shea, 1991). A new rodent (Thomasomys onkiro) of the same family with the African giant pouched rat was described by Luna and Pacheco (2002). According to the authors, the mean length of the longest mystacial vibrissa in Thomasomys onkiro, in absolute terms, was 38.33 $\mathrm{mm}$, and the mean zygomatic breadth (equivalent to width of skull in the present study) was $15.68 \mathrm{~mm}$. Thus, it can be deduced that the mean relative vibrissal length of Thomasomys onkiro was 2.44. The mean relative vibrissal length of two other species described by Luna and Pacheco (2002), Thomasomys silvestris and Thomasomys caudivarius, were 2.90 and 2.63 , respecttively. These values are all less that the 3.16 reported in the present study, for the African giant pouched rat. Furthermore, Klauer et al. (1997) observed that the mystacial vibrissae in the blind mole rat (a similar nocturnal and burrowing rodent as the African giant pouched rat) are generally short and thin, so that, from a macroscopic view, they could be hardly distinguished from other hairs. Again, this contradicts the gross observation of the mystacial vibrissae of the African giant pouch-ed rat, in the present study. It is expected that nocturnal animals should possess long mystacial vibrissae, to offer a good tactile sense as compensation for poor visual sense. However, on the contrary, it has been reported that some burrowing rodents possess short vibrissae (Ahl, 1987; Klauer et al., 1997; Luna and Pacheco, 2002), probably, due to the mechanical impact of the burrows. The African giant pouched rat is a burrowing and a nocturnal rodent. The present study recorded well developed and long mystacial vibrissae in the rodent. This is expected for an enhanced tactile sense due to their poor vision. However, mechanical 
impact of the burrow on the mystacial vibrissae of the African giant pouched rat may be minimal, thus does not affect the length of the mystacial vibrissae adversely. This is unlike what was obtained in other burrowing rodents with relatively short mystacial vibrissae.

Aplin et al. (2003) stated that mystacial vibrissae in rodents are arranged in 7 or more rows, the placement of which is fairly constant within and between species. However, the pattern of arrangement of the mystacial vibrissae in the present study, which is similar with that of Wistar rats (Simons, 1978) and blind mole rats (Klauer et al., 1997) in which they are organised in $5-6$ rows on each side of the face, contradicts the report of Aplin et al. (2003).

\section{Conclusion}

The study has established that the mystacial vibrissa in the African giant pouched rat is very long and well developed with thick cortex and external dermal sheaths, necessary for tactile sense. This will help the rodent to navigate within the burrow without much dependence on sight, so that it can move forward and backward through the underground tunnels. The well organized vibri- ssae will also help the rodent during extractive foraging and in detecting objects that are near to their face.

\section{Acknowledgement}

The authors wish to acknowledge the leading contributions of Professors S. A. Ojo and J. O. Ayo of the Departments of Veterinary Anatomy and Veterinary Physiology/Pharmacology, Ahmadu Bello University, Zaria, respectively. We also appreciate the efforts of Mr. Adetiba Bamidele of the Histology Unit, Department of Human Anatomy, in preparing the slides. 
Table 1: Gross-morphometric values of the mystacial vibrissae in the African giant pouched rat

\begin{tabular}{cccccc}
\hline Animal & $\begin{array}{c}\text { Number of } \\
\text { vibrissae on } \\
\text { right face }\end{array}$ & $\begin{array}{c}\text { Number of vi- } \\
\text { brissae on } \\
\text { left face }\end{array}$ & $\begin{array}{c}\text { Absolute vi- } \\
\text { brissal length } \\
(\mathrm{cm})\end{array}$ & $\begin{array}{c}\text { Width of skull } \\
(\mathrm{cm})\end{array}$ & $\begin{array}{c}\text { Relative vi- } \\
\text { brissal } \\
\text { length }\end{array}$ \\
\hline 1 & 31 & 32 & 13.2 & 3.9 & 3.38 \\
2 & 28 & 20 & 9.5 & 3.5 & 2.71 \\
3 & 25 & 31 & 11.0 & 3.6 & 3.06 \\
4 & 31 & 32 & 9.8 & 3.7 & 2.65 \\
5 & 22 & 26 & 9.7 & 3.4 & 2.85 \\
6 & 32 & 34 & 14.0 & 4.0 & 3.5 \\
7 & 20 & 23 & 12.6 & 3.2 & 3.94 \\
\hline Mean $( \pm$ & $27( \pm 1.80)$ & $28.29( \pm 2.01)$ & $11.4( \pm 0.70)$ & $3.61( \pm 0.11)$ & $3.16( \pm 0.18)$ \\
SEM) & & & & & \\
\hline
\end{tabular}
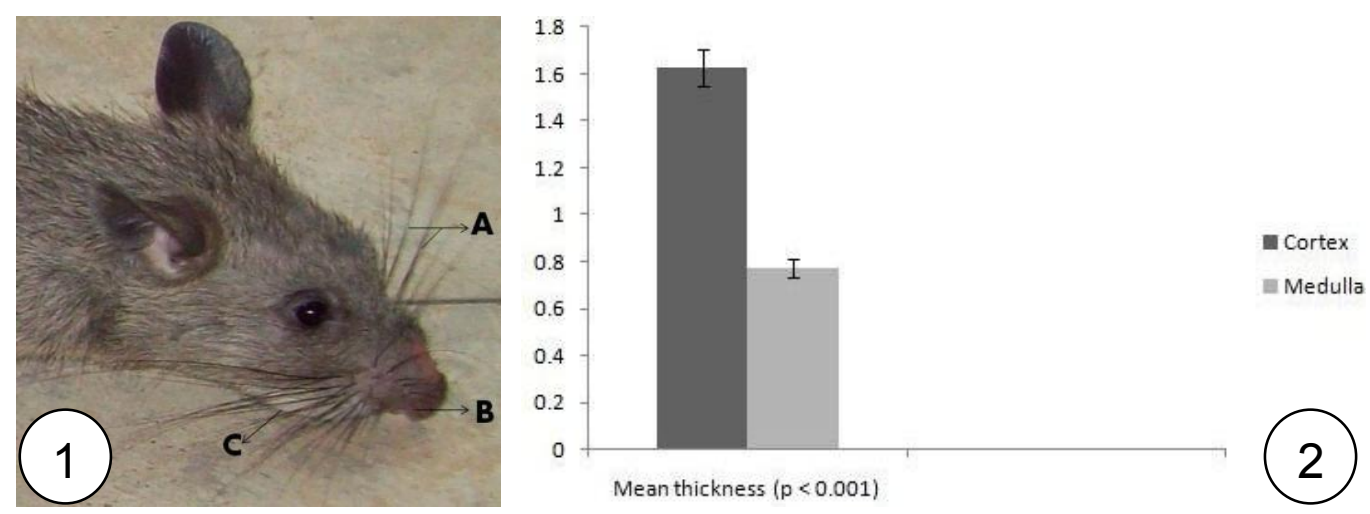

Fig (1): Head of the African giant pouched rat illustrating A: mystacial vibrissae, B: rhinarium, and $\mathrm{C}$ : buccal ridge.

Fig (2): Bar chart representing the difference in means thickness of cortex and medulla of the follicle sinus complex in the African giant pouched rat. 

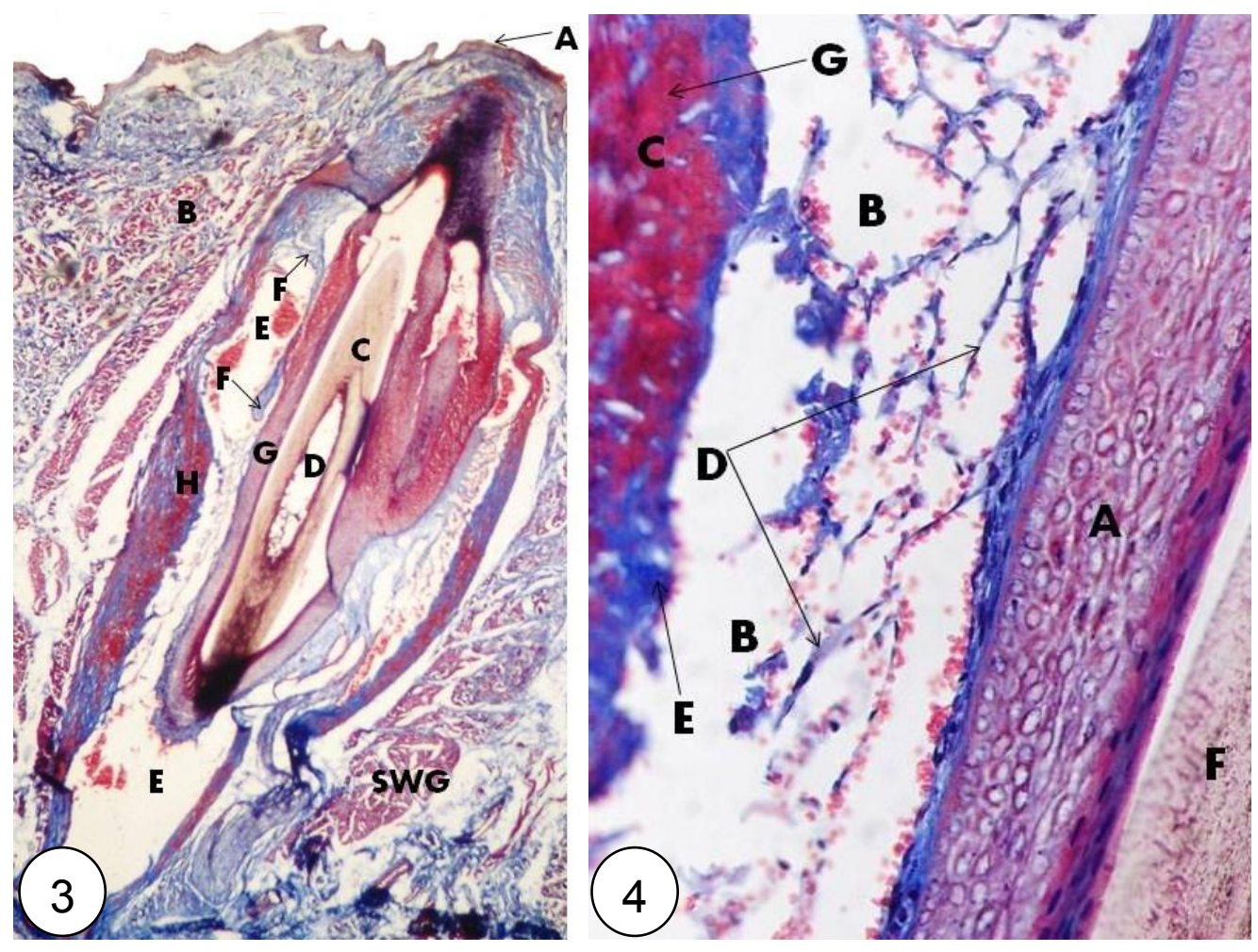

Fig (3): Transverse section of the vibrissal follicle-sinus complex in the African giant pouched rat, illustrating A: Epidermis, B: Collagen fibres, C: Cortex, D: Medulla, E: Sinus, F: Trabeculae, G: Internal dermal sheath, H: External dermal sheath, and SWG: Sweat glands. MT X 40

Fig (4): Transverse section of the vibrissal follicle-sinus complex in the African giant pouched rat, illustrating A: Internal dermal sheath, B: Sinus, C: External dermal sheath, D: Trabeculae, E: Merkel cell, F: Cortex, and G: Collagen fibres. MT X 400 


\section{References}

Ahl, A. S. (1982): Evidence of use of vibrissae in swimming in Sigmodon fulviventer. Animal Behaviour, 30: 1203-1206.

Ahl, A. S. (1987): Relationship of vibrissal length and habits in the Sciuridae. Journal of Mammalogy, 68 (4): 848-853.

Ajayi, S. S. (1975). Observations on the biology, domestication and reproductive performance of the African Giant rat (Cricetomys gambianus, Water-house) in Nigeria. Mammalia, 39: 343364.

Aplin, K. P., Brown, P. R., Jacob, J., Krebs, C. J. and Singleton, G. R. (2003): Field methods for rodent studies in Asia and the Indo-Pacific. ACIAR Monograph No. $100,223 p$.

Bancroft, J. D. and Stevens, A. (1990): Theory and Practice of Histological Techniques, 3rd edn. Edinburgh: Churchill Livingstone

Brecht, M, Preilowski, B. and Merzenich, M. M. (1997): Functional architecture of the mystacial vibrissae. Behavioural Brain Research, 84: 81-97.

Cave, A. J. E. (1969): Hairs and vibrissae in the Rhinocerotidae. Journal of Zoology, 157: 247257.

Dörfl, J. (1985): The innervations of the mystacial region of the white mouse: A topographical study. Journal of Anatomy, 142: 173-184.
Dörfl, J. (1982): The musculature of the mystacial vibrissae of the white mouse. Journal of Anatomy, 135: 147-154

Halata, Z. (1993): Sensory innervation of the hairy skin lightand electronmicroscopic study. Journal of Investigative Dermatology, 10: 75S-81S.

Hyvärinen, H. (1972): On the histology and histochemistry of the snout and vibrissae of the Common Shrew (Sorex araneus L.) Zeitschrift für Zellforschung und mikroskopische, 124: 445-453.

Hyvärinen, H. (1989): Diving in darkness: whiskers as sense organs of the ringed seal (Phoca hispida). Journal of Zoology, 218: 663-678.

Hyvärinen, H., Kangasperko, $H$. and Peura, R. (1976): Functional structure of the carpal and ventral vibrissae of the squirrel (Sciurus vulgaris). Journal of Zoology, 182: 457-466.

Ibe, C. S., Onyeanusi, B. I., Ayo, J. O., Salami, S. O. and Ajayi, I. E. (2010): Preliminary neuroanatomical study of the visual and auditory senses in the African giant pouched rat $(\mathrm{Cr}$ icetomys gambianus Waterhouse-1840). Proceedings of the $35^{\text {th }}$ Annual Conference of the Nigerian Society for Animal Production (NSAP), pp. 134137.

Kemble, E. D., and Lewis, C. (1982): Effects of vibrissal amputation on cricket predation in 
northern grass-hopper mice (Onychomys leucogaster). Bulletin of the Psychonomic Society, 20: 275-276.

Kiernan, J. A. (1990): Histological and histochemical methods: theory and practice. Oxford Pergamon Press, London, pp. 320344.

Klauer, G., Burda, H. and Nevo, E. (1997): Adaptive differentiations of the skin of the head in a subterranean rodent, Spalax ehrenbergi. Journal of Morphology, 233: 53-66.

Krupa, D. J., Matell, M. S., Brisben, A. J., Oliveira, L. M. and Nicolelis, M. A. (2001): Behavioral properties of the trigeminal somatosensory system in rats performing whisker dependent tactile discriminations. Journal of Neuroscience, 21: 57525763.

Krupa, D. J., Wiest, M. C., Shuler, M. G., Laubach, M. and Nicolelis, M. A. (2004): Layer -Specific somatosensory cortical activetion during active tactile discrimination. Science, 304: 19891992.

Luna, L. and Pacheco, V. (2002): A new species of Thomasomys (Muridae: Sigmodontinae) from the Andes of south-eastern Peru. Journal of Mammalogy, 83: 834-842.

Marshall, C. D., Amin, H., Kovacs, K. M. and Lydersen, C. (2006): Microstructure and innervation of the mystacial vibrissal folliclesinus complex in bearded seals,
Erignathus barbatus (Pinnipedia: Phocidae). Anatomical Record, 288A: 13-25.

McWilliams, L. A., Best, T. L., Hunt, J. L. and Smith, K. G. (2002): Eumops dabbenei. Mammalian Species, 707: 1-3.

Morris, B. (1963): Notes on the Giant rat (Cricetomys gambianus) in Nyassaland. African Wild Life, 17: 103-107.

Musser, G. G. and Durden, L. A. (2002): Sulawesi rodents: descryption of a new genus and species of Murinae (Muridae, Rodentia) and its parasitic new species of sucking louse (Insecta, Anoplura). American Museum Novitates, 3368: 1-50.

Nevo, E. and Reig, O. A. (1990): Evolution of subterranean mammals at the organismal and molecular levels. A. R. Liss, New York.

Nomina Anatomica Veterinaria (2005): International Committee on Veterinary Gross Anatomical Nomenclature. 5th Edition. Hannover, Columbia.

O'Shea, T. J. (1991): Xerus rutilus. Mammalian Species, 370: 1-5.

Rasmussen, L. E. L. and Munger, B. L. (1996): The sensorineural specializations of the trunk tip (finger) of the Asian elephant, Elephas maximus. Anatomical Record, 246: 127-134.

Rice, F., Mance, A. and Munger, B. L. (1986): A comparative light microscopic analysis of the sensory innervation of the mystacial pad. I. Innervation of 
vibrissal follicle-sinus complexes. Journal of Comparative Neurology, 252: 154-174.

Schiffman, H. R., Lore, R. Passafiume, J. and Neeb, R. (1970): Role of vibrissae for depth perception in the rat (Rattus norvegicus). Animal behaviour, 18: 290-292.

Simons, D. J. (1978): Response properties of vibrissa units in rat somatosensory neocortex. Journal of Neurophysiology, 41: 798-820.

Smithers, R. H. N. (1985). The mammals of the southern African subregion. Quarterly Review of Biology, 60 (3): 362.

Strozik, E. and Festing, M. F. W. (1981): Whisker trimming in mice. Laboratory Animal, 15: 309-312.

Woolsey, T. A., Durham, D., Harris, R., Simons, D. J. and Valentino, K. (1981): Somatosensory development. In: The development of perception: psychobiological perspectives (Aslin, R. N, Pisani, D. B., eds), pp 259292. New York: Academic.

Yanli, B., Wei, Z., Yanchun, X., Jun, Z. and Xiaoming, T. (1998): Relationship between structure and function of mammalian vibrissa. Journal of Forestry Research, (9): 273-282.

Yildiz, D., Gultiken, M. E. and Karahan, S. (2004): The scaning electron and light microscopic structure of bovine tactile hair. Anatomia Histologia Embryologia, 33: 304-308.
Young, R. D. and Oliver, R. F. (1976): Morphological changes associated with the growth cycle of vibrissal follicles in the rat. Journal of Embryology and Experimental Morphology, 363: 597-607.

\footnotetext{
Correspondence to:

Dr. Chikera Samuel Ibe

Department of Veterinary Anatomy

Ahmadu Bello University

Zaria

Nigeria

Phone: +2348032882105

E-mail: writechikera@yahoo.com
} 